\title{
OPEN Epilepsy lifetime prevalence in Iran: a large population- based national survey
}

\begin{abstract}
Hossein Pakdaman ${ }^{1}$, Ali Amini Harandi ${ }^{1 凶}$, Koroush Gharagozli ${ }^{1}$, Farshid Alaeddini ${ }^{1}$, Akram Esfandani ${ }^{1}$, Seyed Hamidreza Mirbehbahani ${ }^{1}$, Taher Doroudi ${ }^{2}$, Pirhossein Kolivand ${ }^{2}$, Parviz Bahrami ${ }^{2} \&$ Hadi Kazemi ${ }^{2}$

Epilepsy has garnered increased public health focus because patients who suffer from epilepsy experience pronounced and persistent health and socioeconomic disparities despite treatment and care advances. The epidemiology of epilepsy is diverse in different countries and regions. This nationwide population-based cross-sectional study was conducted to determine the life time prevalence and health related factors of epilepsy for the first time in Iran through a two-phase doorto-door survey method. In phase I, a screening for epilepsy was performed on 68,035 people. Then in phase II, after the neurological evaluation of participants and reviewing medical records, 1130 subjects with epilepsy was confirmed. The life time prevalence of epilepsy was achieved to be 16.6 per 1000 people $(95 \% \mathrm{Cl} 15.4-17.8)$ with the average age onset $19.1 \pm 21.1$ (active prevalence 9.5 per 1000 people). Focal seizure (59.3\%), generalized epilepsy (38\%) and unknown types of epilepsy (2.7\%) were detected among participants. The overall life time prevalence of febrile convulsion was 4.1 per 1000 people. The frequency of attacks per year and per month were $3.0 \pm 1.6$ and $0.5 \pm 0.1$, respectively. Age-specific life time prevalence was highest among the age group of 15-19 years old [32.7 per 1000 persons $(95 \% \mathrm{Cl} 29.1-36.8)]$ and it was higher in male (53.8\%) than female (46.2\%) participants. Our results showed that the life time prevalence of epilepsy in Iran is higher than worldwide average.
\end{abstract}

Epilepsy has garnered increased public health focus because patients who suffer from epilepsy experience pronounced and persistent health and socioeconomic disparities despite treatment and care advances. The epidemiology of epilepsy is diverse in different countries and regions ${ }^{1}$. The lifetime prevalence of epilepsy varies between 3.5 and 10.7 per 1000 persons in developed countries, and from 0.9 to 74.4 per 1000 persons in Asia, sub-Saharan Africa, and Latin America ${ }^{2,3}$. Furthermore, epilepsy life time prevalence is higher in rural areas than urban centers ${ }^{4}$. Vast numbers of risk factors besides miscellaneous methodology are partially at fault of abovementioned differences in epidemiology of epilepsy in previous researches. In addition, diagnosis of epilepsy is highly dependent on the patient history and in the lack of a precise route, differences in the criteria that were utilized in the surveys intensify the differences in the epidemiological findings.

The epidemiological and clinical features of the disorder are diverse in different races and ethnicities. Although there are various reports on prevalence of epilepsy in different regions, large nationwide survey in the epidemiology of epilepsy has not conducted in Iran. Iran is one of the most influential middle-east-located country in its region with the income level 3 since 1955, so far and little has been discovered about the epidemiological and clinical features of epilepsy in Iranian population. In the light of previous sparse-population studies that were proposed in Iran, life time prevalence of epilepsy was estimated to be circa 50 per 1000 people in a meta-analysis ${ }^{5}$.

The present study is the first nationwide study which provided updated national and modeled state-specific numbers of active epilepsy cases. Moreover, this survey was proposed in order to clarify and determine the life time prevalence of epilepsy among both sexes, besides the most common risk factors, etiologies, the mean age of onset of epilepsy, the pharmacotherapy approach of Iranian neurologists and the average expenditure paid off by the patients.

Public health practitioners, health care providers, policy makers, epilepsy researchers, and other epilepsy stakeholders, including family members and people with epilepsy, can use these findings to ensure that evidencebased programs meet the complex needs of adults and children with epilepsy and reduce the disparities resulting from it.

${ }^{1}$ Brain Mapping Research Center, Shahid Beheshti University of Medical Sciences, Tehran, Iran. ${ }^{2}$ Shefa Neuroscience Research Center, Khatam-Ol-Anbia Hospital, Tehran, Iran. ${ }^{\varpi}$ email: ali.amini.harandi@gmail.com 


\begin{tabular}{|l|l|}
\hline Gender N (\%) \\
\hline Male (34,290) & $50.4 \%$ \\
\hline Female (33,745) & $49.6 \%$ \\
\hline Age (year) & $36.2 \pm 19.8$ \\
\hline Mean (SD) & $80.2 \%$ \\
\hline Urban residents (54,564) & $19.8 \%$ \\
\hline Rural residents (13,471) & $8.4 \pm 7.6$ \\
\hline Mean years of education (SD) &
\end{tabular}

Table 1. Demographics of the participants.

\begin{tabular}{|l|l|l|l|}
\hline Age groups (year) & Male (per 1000 persons) & Female (per 1000 persons) & Total (per 1000 persons) \\
\hline $0-4$ & 13.0 & 24.1 & 18.8 \\
\hline $5-9$ & 17.3 & 3.3 & 10.8 \\
\hline $10-14$ & 23.4 & 14.6 & 19.2 \\
\hline $15-19$ & 45.7 & 18.7 & 32.7 \\
\hline $20-29$ & 20.5 & 12.9 & 16.6 \\
\hline $30-39$ & 11.5 & 10.7 & 11.1 \\
\hline $40-49$ & 13.0 & 22.5 & 17.8 \\
\hline $50-59$ & 23.0 & 16.9 & 19.8 \\
\hline $60-69$ & 13.7 & 16.1 & 14.9 \\
\hline $70-79$ & 15.4 & 18.9 & 17.0 \\
\hline$\geq 80$ & 21.5 & 35.7 & 27.1 \\
\hline Life-time prevalence & $17.8(16.0-19.5$ CI 95\%) & $15.5(13.8-17.2$ CI 95\%) & 16.6 (15.4-17.8 CI 95\%) \\
\hline
\end{tabular}

Table 2. Correlations between sex and age of participants on the life time prevalence.

\section{Results}

Finally, 68,035 residents of considered areas of the present study were screened in the first phase of the study (Table 1). The mean age of participants was $36.2 \pm 19.8$ (mean \pm SD). The mean years of education was $8.4 \pm 7.6$ and $50.4 \%$ of participants were male. Moreover, $80.2 \%$ of persons were from urban areas. Overall, $5.8 \%$ of the individuals were positive responders (who answered 'yes' to at least one of the epilepsy-related questions of the questionnaire). Our analysis revealed a remarkable correlation between the age and sex of the positive responders as compared with the age $(p<0.0001)$ and sex $(p=0.038)$ of the negative responders (who answered 'no' to all of the epilepsy-related questions) (Table 2 and Fig. 1).

At second phase positive screened subjects were reviewed by expert neurologists and 1130 patients was confirmed as epileptic according to inclusion criteria in which $608(53.8 \%)$ were male and $522(46.2 \%)$ were female. Accordingly, the life time prevalence of epilepsy was 16.6 per 1000 people (95\% CI 15.4-17.8) in Iran and active prevalence was $57.4 \%$ (9.5 per 1000 people). In male participants the life time prevalence was 17.8 per 1000 people (95\% CI 16.0-19.5). It was calculated 15.5 per 1000 persons (95\% CI 13.8-17.2) in female group. There was no difference between male and female in prevalence. The average age of epilepsy onset was 19.1 \pm 21.1 . The frequency of attack per year and per month were $3.0 \pm 1.6$ and $0.5 \pm 0.1$, respectively.

About $67 \%$ of patients were symptom free since the last year in which $23 \%$ of them was in remission for at least two years. It was revealed that $18.8 \%$ of patients suffered from refractory epilepsy (i.e., more than 2 seizures per year). In the last year, $14.2 \%$ of patients had one attack. Moreover, we found that $5.8 \%$ patients had more than 1 attacks per month.

In addition to that, our data demonstrated that most of the patients (59.3\%) suffered from focal epilepsy, in which $42.3 \%$ of them complicated to generalized seizure. About $28.3 \%$ and $21.7 \%$ of patients who suffered from partial seizure, declared that their attacks were manifested by staring and aura, respectively. Generalized epilepsy was found in $38 \%$ patients. In approximately $2.7 \%$ of patients were of unknown types of epilepsy. The overall life time prevalence of febrile convulsion was 4.1 per 1000 people (4.8 per 1000 in male and 3.4 per 1000 in female patients) (Table 3 ).

Age-specific life time prevalence was highest among the age group of 15-19 years old [32.7 per 1000 persons (95\% CI 29.1-36.8)] and it was remarkably higher in male participants [ 45.7 per 1000 persons (95\% CI 39.6-50.0)] than female participants (18.7 per 1000 persons (95\% CI 17.0-19.7)). In view of aetiology, we determined an underlying aetiology in $50.6 \%$ of patients which could be categorised in of the following aetiological groups including trauma (21.9\%), stroke (7.6\%), infectious diseases $(5.7 \%)$, brain tumours $(5.3 \%)$ and others $(10.1 \%)$. Therefore, trauma including head trauma and neurosurgical complications was determined as the most potential cause. 


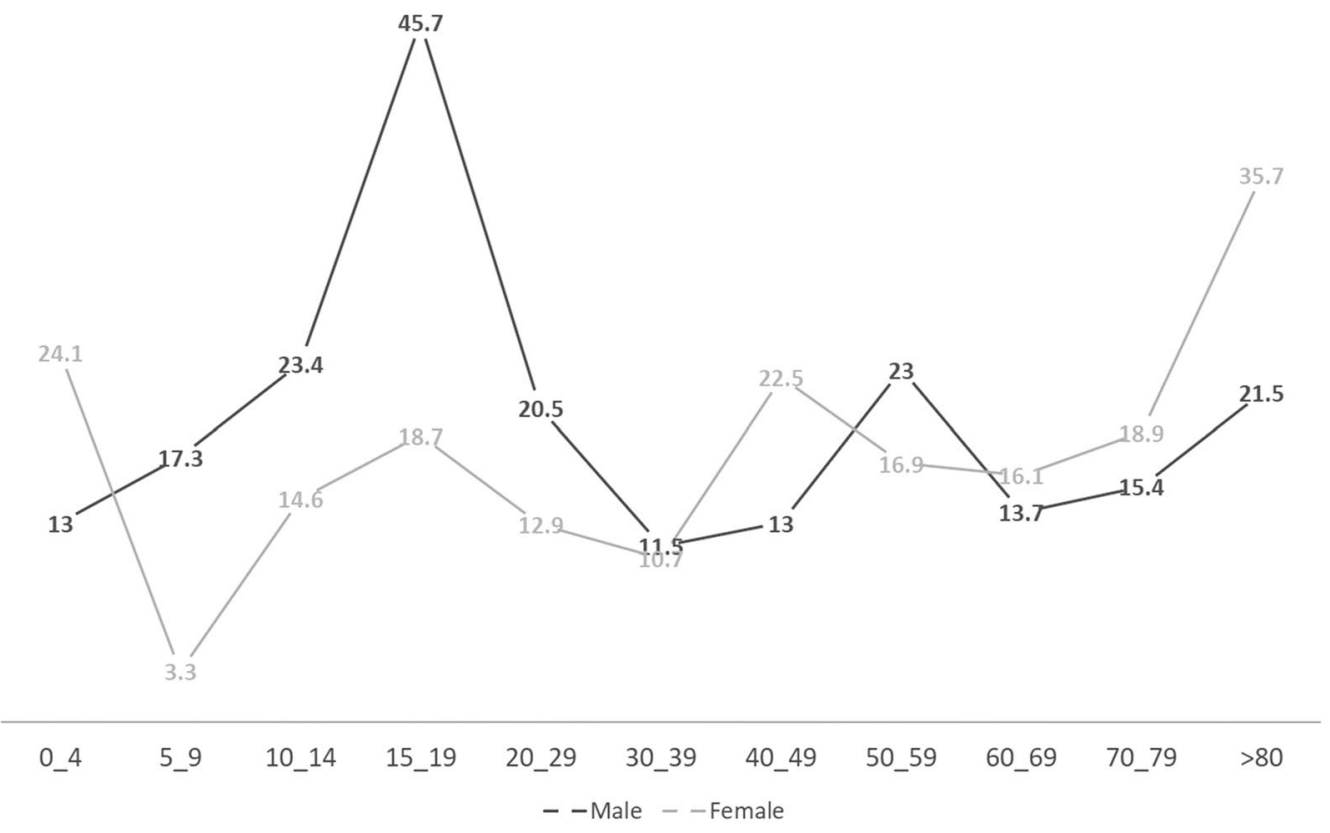

Figure 1. The life time prevalence of epilepsy in age and sex groups.

\begin{tabular}{|l|l|l|l|}
\hline Types of epilepsy & Total N(\%; CI 95\%) & Male (CI 95\%) & Female (CI 95\%) \\
\hline Generalized epilepsy & $429(38 \% ; 36.0-40.0)$ & $37.9 \%(35.3-40.7)$ & $38 \%(35.0-41.0)$ \\
\hline Focal epilepsy & $670(59.3 \% ; 57.3-61.3)$ & $59 \%(56.2-61.8)$ & $59.6 \%(56.6-62.6)$ \\
\hline Unknown & $31(2.7 \% ; 2.0-3.4)$ & $3.1 \%(2.2-4.0)$ & $2.4 \%(1.4-3.4)$ \\
\hline
\end{tabular}

Table 3. Types of epilepsy.

\begin{tabular}{|c|c|c|c|c|c|c|}
\hline \multirow{13}{*}{$\begin{array}{l}\text { Received Antiepileptic } \\
\text { medication }\end{array}$} & \multirow{13}{*}{ (585) 51.8\% } & \multirow{8}{*}{$\begin{array}{l}\text { Single-drug pharmaco- } \\
\text { therapy }\end{array}$} & \multirow{8}{*}{ (362) $61.9 \%$} & Valproate sodium & 13.6 & 22 \\
\hline & & & & Phenytoin & 11.7 & 19 \\
\hline & & & & Carbamazepine & 10.5 & 17 \\
\hline & & & & Levetiracetam & 9.9 & 16 \\
\hline & & & & Lamotrigine & 6.8 & 11 \\
\hline & & & & Phenobarbital & 4.3 & 7 \\
\hline & & & & Others & 4.9 & 8 \\
\hline & & & & Total & $61.9 \%$ & 100 \\
\hline & & \multirow{5}{*}{$\begin{array}{l}\text { Multiple-drug pharmaco- } \\
\text { therapy }\end{array}$} & \multirow{5}{*}{ (223) $38.0 \%$} & Phenytoin + Phenobarbital & 7.6 & 20 \\
\hline & & & & $\begin{array}{l}\text { Valproate sodium + Carba- } \\
\text { mazepine }\end{array}$ & 6.4 & 17 \\
\hline & & & & $\begin{array}{l}\text { Valproate sodium + Leveti- } \\
\text { racetam }\end{array}$ & 6.4 & 17 \\
\hline & & & & Others & 14.8 & 39 \\
\hline & & & & Total & $38.0 \%$ & 100 \\
\hline $\begin{array}{l}\text { Not Received Antiepileptic } \\
\text { medication }\end{array}$ & & & (545) $48.2 \%$ & & & \\
\hline
\end{tabular}

Table 4. Epilepsy Pharmacotherapeutics in Iran.

Circa half of the patients (51.8\%) declared that they received antiepileptic drugs (AEDs). In further details, $61.9 \%$ of them were on single-drug pharmacotherapy while $38 \%$ of the patients were on multiple-drug pharmacotherapy (11.9\% of them received more than 3 AEDs) (Table 4 ).

From the socio-economical aspect, our data disclosed that the out-of-pocket expenses of physician office visit/ ward round and medication were \$76 per month (circa \$0.71-\$284.69 monthly). 


\section{Discussion}

This nationwide illustrative, population-based survey depicted that the prevalence of epilepsy in Iran in the present study population was 16.6 per 1000 people. The life time prevalence of epilepsy in this study was remarkably lower than other small conducted similar studies in Iran due to the large representative sample size that was used in the present study. Furthermore, our results concluded that the life time prevalence of epilepsy in Iran is superior to that compared with global life time prevalence of epilepsy in $2016^{6}$, probably due to the high prevalence of traumatic disasters especially road traffic injuries, occupational and the Iran-Iraq war injuries ${ }^{7}$. In addition, the life time prevalence of epilepsy in Iran was higher than developed countries including USA, Canada, Japan, France, Germany and Israel ${ }^{6}$. Moreover, in order to more accurate interpret our findings, the author have a tendency to compare our results with other nationwide studies (Table 5). Certainly, our neighbourhood countries particularly Turkey, Afghanistan and Iraq were exemplified to comparison due to our similarities in culture, healthcare system and socioeconomic states. However, lack of nationwide studies in neighbours and totally Middle East made it unachievable. Despite that, the increment in the rate of urbanization and westernization in Iran in the last 90 years, probably enhanced the comparison of Iran status with other western countries. As it was discussed previously, Beghi and colleagues estimated the global prevalence of epilepsy $0.6215 \%$ in $2016^{6}$. Their study mainly focused on idiopathic and conditions secondary to infectious diseases including meningitis, tetanus, malaria, cysticercosis 6 . Despite their finding, probably due to improvement in the control of infectious diseases in $\operatorname{Iran}^{8}$, our results did not conclude to a remarkable participation of these mechanisms in the life time prevalence of epilepsy in Iran. Nevertheless, the active prevalence of idiopathic epilepsy in Iran may be higher than the global, $2.7 \%$ against $0.038 \%$, respectively ${ }^{6}$. As it was achieved by the present study, the prevalence of all active epilepsy (both idiopathic and secondary) was 9.5 persons per 1000 which is higher than the global prevalence of all active epilepsy in 2016 (6.215 persons per 1000 $)^{6}$. The prevalence of active epilepsy is highly variable between countries due to local distribution of risk factors. This point is exemplified by the paper of Beghi ${ }^{9}$, in which the prevalence of active epilepsy was compared between low/middle- and high-income countries. He concluded that the prevalence of active epilepsy in the low/middle-income countries was higher than high-income countries ( 8.75 vs. 5.18 persons per 1000, respectively). Therefore, socioeconomic risk factors may be the major determinant of the prevalence of active epilepsy. This point is clearly evident by Ngugi and colleagues' paper ${ }^{4}$. They found not only the higher prevalence of active epilepsy in developing countries than developed countries but also higher prevalence in the rural areas of the developing countries as compared with the urban areas of the same countries.

From the aspect of age and sex as risk factors that influence the life-time prevalence of epilepsy, we found that the life time prevalence of epilepsy was highest in the young who aged between 15 and 19 years old. Our finding is not exactly in harmony with previous studies. In other words, the life time prevalence of epilepsy was found to be lowest in the early life; nonetheless, we concluded that the life time prevalence of the epilepsy is lowest in the third decade of the life ${ }^{1}$. In addition to that, as it is depicted by our results, there was an increment trend toward the prevalence of epilepsy from the fourth decade to the sixth decade, then the life time prevalence of epilepsy reduced in the sixth decade of the life. Henceforth, the life time prevalence of epilepsy increased from the age 70 until the end of life. Despite our finding, similar studies in Europe and other industrialised countries revealed a decrement in the life time prevalence of epilepsy in $3^{\text {rd }}$ decade of life and a plateau state thereafter ${ }^{1,10}$.

Despite the above-mentioned findings in Europe, Weatherburn and colleagues disclosed an increment in the prevalence of epilepsy with age increment in Scotland in the population of older than 14 years old ${ }^{11}$. Nevertheless, we did not conclude to a remarkable difference among the children, younger, middle and elder adults, as it was reported a twofold higher life time prevalence of epilepsy in children and younger adults as compared with middle aged and elder adult in the middle east ${ }^{12}$. In this study, the mean age of onset of seizures was 19.1 years old which is in approximately in harmony with previous studies ${ }^{13}$.

This study is the first study in Iran that accurately assessed the life time prevalence in the age groups. Previous studies usually classified the prevalence of epilepsy by age as upper and lower 20 years old ${ }^{14}$. The main deficit of previous literature was that they did not provide a detailed life time prevalence estimation classified by age and sex, probably due to their limitation of sources and the size of their sample ${ }^{15-18}$. Hence, above-mentioned items were considered in the design of present study. In fact, there is a controversy that sex can influence the prevalence of epilepsy ${ }^{19}$. In the present study, it was revealed that epilepsy is more prevalent among male rather than female. This finding is in concert with previous literature ${ }^{1,20}$. Interestingly, the life time prevalence of epilepsy was remarkably higher in boys aged between 5 and 9 years than same-aged girls. In addition, men aged 15 to 19 year were more susceptible to epilepsy. However, women aged more than 80 years old showed a higher tendency toward epilepsy than other life period.

As it was not evident by previous literature, this study is distinguished from previous studies in providing of above-mentioned information. As compared with similar studies in the middle east, we also found that epilepsy life time prevalence is overall higher in male than female patients ${ }^{12}$. This finding may be attributable to the specific social and cultural atmosphere of Middle East, in which women encourage to conceal their diseases in order not to become isolated from the society and to improve their chance of marriage ${ }^{19,20}$.

In the present study also, we endeavoured to detect the prevalence of epilepsy as considered by types. Most of the Iranian patients in this study were diagnosed to suffer from focal epilepsy. This is interesting when generalized epilepsy is more prevalent in Middle East as it was evident by previous regional-wide studies ${ }^{13}$. The classification of epilepsy is highly dependent on the complex medical technology, and it may be the cause of differences among different studies.

This study is the first study in Iran that determined the exact pharmacotherapeutics received by patients. Most of the patients that were assessed in this study took a single drug monotherapy as it was revealed by previous studies in the middle east ${ }^{13}$. Previously, carbamazepine was determined to be the most common-prescribed 


\begin{tabular}{|c|c|c|c|c|c|c|}
\hline Study & Study year & Population size & Country/Region & Life-time prevalence (\%) & Epilepsy types & Aetiologies \\
\hline Beghi et al. ${ }^{6}$ & 2016 & $27,737,043$ & Global & 0.6215 & Idiopathic, Secondary & $\begin{array}{l}\text { Meningitis, tetanus, malaria, } \\
\text { cysticercosis, cystic echi- } \\
\text { nococcosis, preterm birth } \\
\text { complications, neonatal } \\
\text { encephalopathy, neonatal } \\
\text { sepsis, and neonatal haemo- } \\
\text { lytic disease }\end{array}$ \\
\hline Zack et al. $^{29}$ & 2015 & $3,470,000$ & USA & 1.2 & Active & Not determined \\
\hline Hamer et al..$^{30}$ & 2009 & 634,566 & Germany & 0.91 & $\begin{array}{l}\text { Prevalence of patients receiv- } \\
\text { ing antiepileptic medication }\end{array}$ & Not determined \\
\hline Serrano-Castro ${ }^{31}$ & 2012 & 1741 & Spain & 1.487 & $\begin{array}{l}\text { Partial seizure with/without } \\
\text { secondary generalization, } \\
\text { generalized tonic-clonic } \\
\text { seizures, myoclonic seizures, } \\
\text { idiopathic epilepsy, crypto- } \\
\text { genic epilepsy }\end{array}$ & Not determined \\
\hline Giussani et al. ${ }^{32}$ & 2011 & 912,458 & Italy & 0.79 & Not determined & Not determined \\
\hline Keränen et al. ${ }^{33}$ & 1989 & 2080 & Eastern Finland & 0.63 & $\begin{array}{l}\text { Active epilepsy, secondary to } \\
\text { organic causes, general- } \\
\text { ized seizure, partial seizure, } \\
\text { unclassified seizure }\end{array}$ & Not clarified \\
\hline Joensen $^{34}$ & 1986 & 43,609 & Faroes, Denmark & 0.78 & $\begin{array}{l}\text { Generalized epilepsy includ- } \\
\text { ing primary (grand mal, petit } \\
\text { mal, juvenile myoclonus) and } \\
\text { secondary (west syndrome, } \\
\text { Lennox-Gastaut syndrome), } \\
\text { partial seizure }\end{array}$ & Not determined \\
\hline Olafsson et al. ${ }^{35}$ & 1999 & 428 & Rural Iceland & 0.48 & $\begin{array}{l}\text { Partial seizure (simple par- } \\
\text { tial, complex partial, partial } \\
\text { secondarily generalized), } \\
\text { primary generalized seizure } \\
\text { (absence, myoclonic with or } \\
\text { without other types, major } \\
\text { motor seizure alone), other } \\
\text { major motor seizures without } \\
\text { aura, not classified }\end{array}$ & $\begin{array}{l}\text { Idiopathic, remote symp- } \\
\text { tomatic (cerebrovascular } \\
\text { disease, MR/CP, infections, } \\
\text { trauma), progressive symp- } \\
\text { tomatic (primary and meta- } \\
\text { static neoplasms), degenera- } \\
\text { tive diseases (dementia) }\end{array}$ \\
\hline Forsgren $^{36}$ & 1992 & 713 & Northern Sweden & 0.55 & $\begin{array}{l}\text { Partial seizure (simple, } \\
\text { complex, secondarily gener- } \\
\text { alized), generalized seizure } \\
\text { (tonic-clonic, myoclonic, } \\
\text { absence, other), unclas- } \\
\text { sifiable }\end{array}$ & $\begin{array}{l}\text { Ischemic and haemorrhagic } \\
\text { cerebrovascular disorders, } \\
\text { trauma, tumour, infections, } \\
\text { pre/perinatal asphyxia, } \\
\text { prematurity, chromosomal } \\
\text { aberration (Down syndrome, } \\
\text { fragile X, (46XX, 13q+)), } \\
\text { Rett syndrome, idiopathic }\end{array}$ \\
\hline Onal et al. ${ }^{37}$ & 1999 & 2187 & $\begin{array}{l}\text { Rural areas of Istanbul, } \\
\text { Turkey }\end{array}$ & 0.8 & $\begin{array}{l}\text { Partial, generalized, unclas- } \\
\text { sifiable }\end{array}$ & Not determined \\
\hline Aziz et al..$^{38}$ & 1997 & 24,130 & Pakistan & 0.99 & $\begin{array}{l}\text { Generalized tonic-clonic, } \\
\text { simple partial, complex } \\
\text { partial, generalized, absence, } \\
\text { tonic and atonic, myoclonic }\end{array}$ & $\begin{array}{l}\text { Idiopathic, past history of } \\
\text { meningitis, encephalitis, } \\
\text { neonatal jaundice, neonatal } \\
\text { convulsions, hypertension, } \\
\text { ischemic heart disease }\end{array}$ \\
\hline Radhakrishnan et al. ${ }^{39}$ & 2000 & 238,102 & Kerala, South India & 0.49 & Generalized, other & Not determined \\
\hline Al Rajeh et al. ${ }^{40}$ & 2001 & 23,700 & Saudi Arabia & 0.654 & Partial, generalized & $\begin{array}{l}\text { Pre/perinatal encephalopa- } \\
\text { thy, head injury, childhood } \\
\text { neurological infection, stroke } \\
\text { febrile }\end{array}$ \\
\hline Li et al. ${ }^{41}$ & 1983 & 63,195 & China & 0.44 & $\begin{array}{l}\text { Generalized nonconvulsive } \\
\text { (akinetic, atonic), General- } \\
\text { ized convulsive (grand mal), } \\
\text { Partial epilepsy (with or } \\
\text { without impairment con- } \\
\text { sciousness, Multiple types }\end{array}$ & $\begin{array}{l}\text { Brain injury, intracranial } \\
\text { infection, and cerebrovascu- } \\
\text { lar disease }\end{array}$ \\
\hline Guekht et al. ${ }^{42}$ & 2010 & 517,624 & Russia & 0.34 & \begin{tabular}{|l|} 
Generalized \\
(Myoclonic,Atonic, Absence, \\
Tonic, Tonic-clonic) Partial \\
seizures (simple, Complex, \\
Partial (simple and/or com- \\
plex) evolving to generalized)
\end{tabular} & $\begin{array}{l}\text { Head injuries, cerebrovascu- } \\
\text { lar diseases, CNS infection, } \\
\text { Pre/perinatal disorders, } \\
\text { neurodegenerative disorders, } \\
\text { tumours, unknown }\end{array}$ \\
\hline Osuntokun et al. ${ }^{43}$ & 1982 & 18,954 & Igbo-Ora, Nigeria & 0.5 & $\begin{array}{l}\text { Generalized (Tonic- } \\
\text { clonic, Petit mal,Grand } \\
\text { mal, Partial (Simple, } \\
\text { Complex),Unclassified }\end{array}$ & Not determined \\
\hline Tekle-Haimanot et al. ${ }^{44}$ & $1986-1988$ & 60,820 & $\begin{array}{l}\text { Meskan and Mareko, } \\
\text { Ethiopia }\end{array}$ & 0.52 & $\begin{array}{l}\text { Generalized tonic-clonic } \\
\text { seizures, Partial, absence, } \\
\text { unclassified }\end{array}$ & Not determined \\
\hline \multicolumn{7}{|l|}{ Continued } \\
\hline
\end{tabular}




\begin{tabular}{|l|l|l|l|l|l|l|}
\hline Study & Study year & Population size & Country/Region & Life-time prevalence (\%) & Epilepsy types & Aetiologies \\
\hline Rwiza et al.45 & 1989 & 18,000 & Ulanga, Tanzania & 1.02 & $\begin{array}{l}\text { Partial (Simple, Complex, } \\
\text { secondarily generalized), } \\
\text { generalized (Absence, Tonic- } \\
\text { clonic, Myoclonic, Tonic, } \\
\text { Atonic), Unclassifiable }\end{array}$ & $\begin{array}{l}\text { Idiopathic, Febrile convul- } \\
\text { sion, Unspecified encepha- } \\
\text { litis, Birth trauma, Cerebral } \\
\text { malaria, Meningitis, Head } \\
\text { trauma, Cerebrovascular } \\
\text { disease, Suspected tumour }\end{array}$ \\
\hline Birbeck et al. ${ }^{46}$ & $2000-2001$ & 799 & & 1.45 & Not determined & Not determined \\
\hline
\end{tabular}

Table 5. A comparison of epilepsy life time prevalence in nationwide scale in other countries/regions.

AEDs, nonetheless, in this study we found that sodium valproate nowadays is the most administered drug. On the one hand, we determined that most of the Iranian patients suffered from focal epilepsy, but on the other, sodium valproate which is preferable drug for generalized seizure was the most common-used drug. As it was disclosed by previous studies, carbamazepine is highly effective for focal seizure therapy ${ }^{21,22}$.

Aetiologically, we found that trauma exemplified as head trauma and complications of neurological surgery was the most common underlying cause, however, previously, fever, tonic-colonic convulsions and epilepsy were found to be the predominant causes of epilepsy ${ }^{5}$. Our study was highly successful to determine an aetiology in circa half of the participants, while previous studies which assessed all age groups, concluded to a clear aetiology in $14 \%$ to $39 \%$ of cases $^{23}$. To our knowledge, this study is the first study attempted to clarify the out-of-pocket expenses of patients with epilepsy in Iran. It is evident that epilepsy is more prevalent among low-income people ${ }^{24}$.

Our nationwide illustrative, population-based survey revealed that the life time prevalence of epilepsy in Iran was lower than other small conducted similar small studies in Iran. However, our results showed that the life time prevalence of epilepsy in Iran is higher than average worldwide prevalence of epilepsy. We hope that further investigations would be run to determine more precisely the effect of socio-economic status of patients with epilepsy on their prognosis and disease procedure in Iran.

\section{Methods and materials}

Study design. This study was designed as a population-based cross-sectional study. It was conducted from 2018 to 2021 in the both urban and rural regions of all provinces of Iran. The country's population according to last statistics provided by the United Nation data is $83,992,949$ in 2020 , of which $71.3 \%$ live in urban areas and $28.7 \%$ in rural areas. Iran is $1648195 \mathrm{~km}^{2}$ and consists of 31 provinces. There are more than 7 ethnic groups which approximately all are Caucasian-white.

Sample size. In Previous study that has been conducted in Tehran, epilepsy life time prevalence estimated 10 per 1000 people $^{25}$. Twenty-five thousand families were selected from 21,049,934 families in country through cluster sampling. In other words, there was 500 clusters of families consisted of 357 urban clusters and 143 rural clusters.

Diagnostic criteria. According to the guidelines for epidemiologic studies on epilepsy ${ }^{26}$, epilepsy was defined as the condition characterized by recurrent (two or more) epileptic seizures, unprovoked by any immediate identified cause. Multiple seizures occurring in a $24-\mathrm{h}$ period were considered a single event. Single epileptic seizures, and epileptic seizures with an obvious precipitant were excluded. Life time prevalence was a diagnosis of epilepsy (recurrent unprovoked seizures) at some point prior to the prevalence period or date. A prevalent case of active epilepsy was defined as a person with epilepsy who has had at least one seizure in the previous 5 years, regardless of antiepileptic drug treatment.

Seizures were classified in accordance with the international classification of epileptic seizures of ILAE ${ }^{27}$, based on the clinical history, age at onset, seizure patterns, evolution of the disease, clinical EEG and neuroradiologic examinations. A seizure was considered focal seizure on the basis of clinical evidence of focal onset, regardless of whether it was secondarily generalized. Remission referred to when epilepsy patients who have never been treated with any antiepileptic drugs were free of seizures for two years or more. Treatment gap was the number of people with active epilepsy not on adequate treatment, expressed as a percentage of total number with active epilepsy.

Related aetiology was accepted while there was strong association between cause and effect i.e., hospital recorded documents, localization (imaging and EEG) and/or time relevancy. Car accidents and war victims were well documented subjects in the head trauma category. If such a strong association was not found, the suspected risk factor was ignored. This strategy was followed by each etiological factor including trauma, stroke, infection, brain tumors and others. Self-report alone was not considered as sufficient criteria. Final decision for each case was made by an expert committee.

Steps of the study. The present study used a two-phase door-to-door survey method. In phase I, a screening instrument for epilepsy was administered to subjects who agreed to participate; in phase II, the neurological evaluation of possible epilepsy was performed by expert neurologists among those subjects who screened positive for that condition in phase I.

Phase I: screening. The field workers composed by local health staffs in the survey were given a standard training. The validated screening questionnaire by Placencia et al. ${ }^{28}$ was used to detect possible cases of epilepsy. 
The health workers who had been trained and could understand the screening questionnaires translated them into ethnic languages and dialects, if the people surveyed could not understand the screening questionnaires written in Persian. All staffs and interviews were trained and examined preceding the initiation of the study in order to ensure their qualifications required for the current study. The screening procedure was conducted during interview so that investigators had to verify that all subjects understood the questions asked in the questionnaire. Each interview was conducted by a native health staff due to the ethnic languages and dialects. Each adult resident in the house was interviewed. The head of the household, usually the husband, and his wife provided information about each child with age less than 14 years old. If necessary, the patients and their families were required to give a detailed demonstration of the seizure. In case of seizure history of family member(s), details were taken from the cases and also from a reliable eyewitness of the ictal event. The screening was completed when all subjects in a certain area were investigated.

Phase II: Diagnosis and confirmation. Individuals whose responses to the questionnaire suggested they might have epilepsy were then scrutinized by a neurologist. Expert neurologists clinically examined these subjects at their residences, and reviewed relevant investigation records if available. The date of onset of seizure was ascertained as accurately as possible. On the basis of these observations, neurologists made the diagnosis of epilepsy and of other forms of seizure disorder and also identified and excluded the false positives. Most of patients with epilepsy were diagnosed through clinical evaluation and reviewing medical records. Experts from department of neurology together discussed the patients with unascertained diagnosis. As for the case of a disagreement among senior neurologists, the clinical, EEG and imaging data of the patients were discussed together to reach a consensus.

Statistical analysis. Data were analysed through SPSS 18 (Chicago, IL). Chi-square and odd ratio were calculated in order to determine the correlation between epilepsy and demographic factors including sex and age.

Ethics approval. The study was approved by the ethical committee of the Shahid Beheshti University of Medical Sciences (IRB code 1395.479). All participants, patients and interviewers gave written informed consent. Informed consent was given from the parents or legal guardians of participants who were under the codified age. All procedures performed in the present study were in accordance with the ethical standards of the institutional and national research committee of the Shahid Beheshti University of Medical Sciences and the 1964 Helsinki declaration and its further updates.

Received: 26 September 2020; Accepted: 8 April 2021

Published online: 03 May 2021

\section{References}

1. Fiest, K. M. et al. Prevalence and incidence of epilepsy: A systematic review and meta-analysis of international studies. Neurology 88(3), 296-303. https://doi.org/10.1212/WNL.0000000000003509 (2017).

2. Radhakrishnan, K. Challenges in the management of epilepsy in resource-poor countries. Nat. Rev. Neurol. 5(6), 323-330. https:// doi.org/10.1038/nrneurol.2009.53 (2009).

3. Ngugi, A. K. et al. Prevalence of active convulsive epilepsy in sub-Saharan Africa and associated risk factors: cross-sectional and case-control studies. Lancet Neurol. 12(3), 253-263. https://doi.org/10.1016/S1474-4422(13)70003-6 (2013).

4. Ngugi, A. K., Bottomley, C., Kleinschmidt, I., Sander, J. W. \& Newton, C. R. Estimation of the burden of active and life-time epilepsy: A meta-analytic approach. Epilepsia 51(5), 883-890. https://doi.org/10.1111/j.1528-1167.2009.02481.x (2010).

5. Sayehmiri, K., Tavan, H., Sayehmiri, F., Mohammadi, I. \& Carson, K. V. Prevalence of epilepsy in Iran: A meta-analysis and systematic review. Iran J. Child Neurol. 8(4), 9-17 (2014).

6. Beghi, E. et al. Global, regional, and national burden of epilepsy, 1990-2016: A systematic analysis for the Global Burden of Disease Study 2016. Lancet Neurol. 18(4), 357-375. https://doi.org/10.1016/S1474-4422(18)30454-X (2019).

7. Bahadorimonfared, A. et al. Trends of fatal road traffic injuries in Iran (2004-2011). PLoS ONE 8(5), e65198. https://doi.org/10. 1371/journal.pone.0065198 (2013).

8. Mirzaei, H. et al. Health status in the Islamic Republic of Iran, Middle East and North Africa countries: Implications for global health. Iran J. Public Health 49(1), 86-95 (2020).

9. Beghi, E. The epidemiology of epilepsy. Neuroepidemiology 54(2), 185-191. https://doi.org/10.1159/000503831 (2020).

10. Forsgren, L., Beghi, E., Oun, A. \& Sillanpää, M. The epidemiology of epilepsy in Europe-A systematic review. Eur. J. Neurol. 12(4), 245-253. https://doi.org/10.1111/j.1468-1331.2004.00992.x (2005).

11. Weatherburn, C. J., Heath, C. A., Mercer, S. W. \& Guthrie, B. Physical and mental health comorbidities of epilepsy: Populationbased cross-sectional analysis of 1.5 million people in Scotland. Seizure 45, 125-131. https://doi.org/10.1016/j.seizure.2016.11. 013 (2017).

12. Benamer, H. T. \& Grosset, D. G. A systematic review of the epidemiology of epilepsy in Arab countries. Epilepsia 50(10), 2301-2304. https://doi.org/10.1111/j.1528-1167.2009.02058.x (2009).

13. Baker, G. A., Jacoby, A., Gorry, J., Doughty, J. \& Ellina, V. Quality of life of people with epilepsy in Iran, the Gulf, and Near East. Epilepsia 46(1), 132-140. https://doi.org/10.1111/j.0013-9580.2005.20704.x (2005).

14. Etemadifar, M. \& Mirabdolbaghe, P. Demographic and clinical characteristics of young epilepsy mortalities in Isfahan. Two Q. South Pediatr. Persian Golf Center Health Res. Boushehr Univ. Med. Sci. 2, 160-164 (2005).

15. Rezaei, A. \& Sh, S. Survey of starting age and gender of epilepsy and effective parameters on the Sina and Ghaem hospitals patients at 1989 till 1995. Rehabil. Mag. 2, 52-57 (2000).

16. Kaheni, S., Riyasi, H., Rezvani Kharashad, M. \& Sharifzadeh Gh, N. S. Prevalence of epilepsy in children at primary schools and awareness of teachers about epilepsy at primary schools of Birjand at 2010. Novel Cares Q. Sci. J. Nurs. Midwifery Birjand Univ. Med. Sci. 3, 135-142 (2011).

17. Nasehi, M., Mahvalati Shamsabadi, F. \& Ghofrani, M. Associated factors in response to treatment in children with refractory epilepsy. J. Babol Univ. Med. Sci. 12(4), 61-66 (2010).

18. Mohammadi, M. R., Ghanizadeh, A., Davidian, H., Mohammadi, M. \& Norouzian, M. Prevalence of epilepsy and comorbidity of psychiatric disorders in Iran. Seizure 15(7), 476-482 (2006). 
19. Banerjee, P. N., Filippi, D. \& Allen Hauser, W. The descriptive epidemiology of epilepsy-a review. Epilepsy Res. 85(1), 31-45. https:// doi.org/10.1016/j.eplepsyres.2009.03.003 (2009).

20. Bharucha, N. E., Bharucha, E. P., Bharucha, A. E., Bhise, A. V. \& Schoenberg, B. S. Prevalence of epilepsy in the Parsi community of Bombay. Epilepsia 29(2), 111-115. https://doi.org/10.1111/j.1528-1157.1988.tb04405.x (1988).

21. Marson, A. G. et al. Carbamazepine versus valproate monotherapy for epilepsy: A meta-analysis. Epilepsia 43(5), 505-513. https:// doi.org/10.1046/j.1528-1157.2002.20801.x (2002).

22. Mattson, R. H., Cramer, J. A. \& Collins, J. F. A comparison of valproate with carbamazepine for the treatment of complex partial seizures and secondarily generalized tonic-clonic seizures in adults. N. Engl. J. Med. 327(11), 765-771. https://doi.org/10.1056/ nejm199209103271104 (1992).

23. Banerjee, P. N., Filippi, D. \& Allen Hauser, W. The descriptive epidemiology of epilepsy-A review. Epilepsy Res. 85(1), 31-45. https://doi.org/10.1016/j.eplepsyres.2009.03.003 (2009)

24. Thurman, D. J., Kobau, R., Luo, Y. H., Helmers, S. L. \& Zack, M. M. Health-care access among adults with epilepsy: The U.S. National Health Interview Survey, 2010 and 2013. Epilepsy Behav. EઐB 55, 184-188. https://doi.org/10.1016/j.yebeh.2015.10.028 (2016).

25. Noorbala, A. A., Bagheri Yazdi, S. A., Yasamy, M. T. \& Mohammad, K. Mental health survey of the adult population in Iran. Br. J. Psychiatry J. Ment. Sci. 184, 70-73. https://doi.org/10.1192/bjp.184.1.70 (2004).

26. Guidelines for epidemiologic studies on epilepsy. Commission on Epidemiology and Prognosis, International League Against Epilepsy (1993). Epilepsia 34(4):592-596. https://doi.org/10.1111/j.1528-1157.1993.tb00433.x

27. Scheffer, I. E. et al. ILAE classification of the epilepsies: Position paper of the ILAE Commission for Classification and Terminology. Epilepsia 58(4), 512-521. https://doi.org/10.1111/epi.13709 (2017).

28. Placencia, M., Sander, J. W., Shorvon, S. D., Ellison, R. H. \& Cascante, S. M. Validation of a screening questionnaire for the detection of epileptic seizures in epidemiological studies. Brain J. Neurol. 115(Pt 3), 783-794. https://doi.org/10.1093/brain/115.3.783 (1992).

29. Zack, M. M. Kobau R (2017) National and state estimates of the numbers of adults and children with active epilepsy-United States. MMWR Morb. Mortal. Wkly. Rep. 66(31), 821-825. https://doi.org/10.15585/mmwr.mm6631al (2015).

30. Hamer, H. M. et al. Prevalence, utilization, and costs of antiepileptic drugs for epilepsy in Germany-A nationwide populationbased study in children and adults. J. Neurol. 259(11), 2376-2384. https://doi.org/10.1007/s00415-012-6509-3 (2012).

31. Serrano-Castro, P. J. et al. Adult prevalence of epilepsy in Spain: EPIBERIA, a population-based study. Sci. World J. 2015, 602710. https://doi.org/10.1155/2015/602710 (2015).

32. Giussani, G. et al. Prevalence and incidence of epilepsy in Italy based on a nationwide database. Neuroepidemiology 43(3-4), 228-232. https://doi.org/10.1159/000368801 (2014).

33. Keränen, T., Riekkinen, P. J. \& Sillanpaa, M. Incidence and prevalence of epilepsy in adults in eastern Finland. Epilepsia 30(4), 413-421. https://doi.org/10.1111/j.1528-1157.1989.tb05320.x (1989).

34. Joensen, P. Prevalence, incidence, and classification of epilepsy in the Faroes. Acta Neurol. Scand. 74(2), 150-155. https://doi.org/ 10.1111/j.1600-0404.1986.tb04642.x (1986).

35. Olafsson, E. \& Hauser, W. A. Prevalence of epilepsy in rural Iceland: A population-based study. Epilepsia 40(11), 1529-1534. https://doi.org/10.1111/j.1528-1157.1999.tb02036.x (1999).

36. Forsgren, L. Prevalence of epilepsy in adults in northern Sweden. Epilepsia 33(3), 450-458. https://doi.org/10.1111/j.1528-1157. 1992.tb01690.x (1992).

37. Onal, A. E. et al. Epilepsy prevalence in a rural area in Istanbul. Seizure 11(6), 397-401. https://doi.org/10.1053/seiz.2001.0665 (2002).

38. Aziz, H., Güvener, A., Akhtar, S. W. \& Hasan, K. Z. Comparative epidemiology of epilepsy in Pakistan and Turkey: Populationbased studies using identical protocols. Epilepsia 38(6), 716-722. https://doi.org/10.1111/j.1528-1157.1997.tb01242.x (1997).

39. Radhakrishnan, K. et al. Prevalence, knowledge, attitude, and practice of epilepsy in Kerala, South India. Epilepsia 41(8), 1027-1035. https://doi.org/10.1111/j.1528-1157.2000.tb00289.x (2000).

40. Al Rajeh, S., Awada, A., Bademosi, O. \& Ogunniyi, A. The prevalence of epilepsy and other seizure disorders in an Arab population: A community-based study. Seizure 10(6), 410-414. https://doi.org/10.1053/seiz.2001.0602 (2001).

41. Li, S. C. et al. Epidemiology of epilepsy in urban areas of the People's Republic of China. Epilepsia 26(5), 391-394. https://doi.org/ 10.1111/j.1528-1157.1985.tb05669.x (1985).

42. Guekht, A. et al. The epidemiology of epilepsy in the Russian Federation. Epilepsy Res. 92(2), 209-218. https://doi.org/10.1016/j. eplepsyres.2010.09.011 (2010).

43. Osuntokun, B. O. et al. Prevalence of the epilepsies in Nigerian Africans: A community-based study. Epilepsia 28(3), 272-279. https://doi.org/10.1111/j.1528-1157.1987.tb04218.x (1987).

44. Tekle-Haimanot, R. et al. Clinical and electroencephalographic characteristics of epilepsy in rural Ethiopia: A community-based study. Epilepsy Res. 7(3), 230-239. https://doi.org/10.1016/0920-1211(90)90020-v (1990).

45. Rwiza, H. T. et al. Prevalence and incidence of epilepsy in Ulanga, a rural Tanzanian district: A community-based study. Epilepsia 33(6), 1051-1056. https://doi.org/10.1111/j.1528-1157.1992.tb01758.x (1992).

46. Birbeck, G. L. \& Kalichi, E. M. Epilepsy prevalence in rural Zambia: A door-to-door survey. Trop. Med. Int. Health TM \& IH 9(1), 92-95. https://doi.org/10.1046/j.1365-3156.2003.01149.x (2004).

\section{Author contributions}

H.P., A.A.H., K.G. and F.A. participated in the study design, neurologic assessments of participants and supervised the study progression. F.A. also analysed the data. A.A.H. also edited and reviewed the manuscript. A.E., S.H.M., T.D., P.K., P.B. and H.K. contributed in data collection and evaluation of the participants.

\section{Funding}

Funding was provided by Shahid Beheshti University of Medical Science (Grant No. 2335_8913).

\section{Competing interests}

The authors declare no competing interests.

\section{Additional information}

Correspondence and requests for materials should be addressed to A.A.H.

Reprints and permissions information is available at www.nature.com/reprints.

Publisher's note Springer Nature remains neutral with regard to jurisdictional claims in published maps and institutional affiliations. 
(c) (i) Open Access This article is licensed under a Creative Commons Attribution 4.0 International cc) License, which permits use, sharing, adaptation, distribution and reproduction in any medium or format, as long as you give appropriate credit to the original author(s) and the source, provide a link to the Creative Commons licence, and indicate if changes were made. The images or other third party material in this article are included in the article's Creative Commons licence, unless indicated otherwise in a credit line to the material. If material is not included in the article's Creative Commons licence and your intended use is not permitted by statutory regulation or exceeds the permitted use, you will need to obtain permission directly from the copyright holder. To view a copy of this licence, visit http://creativecommons.org/licenses/by/4.0/.

(C) The Author(s) 2021 